Published in final edited form as:

Curr Treat Options Oncol. ; 18(12): 70. doi:10.1007/s11864-017-0511-z.

\title{
Diagnosis and Treatment of Aplastic Anemia
}

\author{
Scott A. Peslak, MD, PhD' ${ }^{1}$, Timothy Olson, $\mathrm{MD}, \mathrm{PhD}^{2,3}$, and Daria V. Babushok, $\mathrm{MD}, \mathrm{PhD}^{1,2}$ \\ ${ }^{1}$ Division of Hematology and Oncology, Department of Medicine, Hospital of the University of \\ Pennsylvania, Perelman Center for Advanced Medicine, 3400 Civic Center Blvd, Philadelphia, PA \\ 19406, USA \\ ${ }^{2}$ Comprehensive Bone Marrow Failure Center, Children's Hospital of Philadelphia, 3615 Civic \\ Center Boulevard, Philadelphia, PA 19104 \\ 3Division of Oncology, Department of Pediatrics, Children's Hospital of Philadelphia, 3615 Civic \\ Center Boulevard, Philadelphia, PA 19104
}

\section{Opinion Statement}

Acquired aplastic anemia (AA) is a rare, life-threatening bone marrow failure (BMF) disorder that affects patients of all ages and is caused by lymphocyte destruction of early hematopoietic cells. Diagnosis of AA requires a comprehensive approach with prompt evaluation for inherited and secondary causes of bone marrow aplasia, while providing aggressive supportive care. The choice of frontline therapy is determined by a number of factors including AA severity, age of the patient, donor availability, and access to optimal therapies. For newly diagnosed severe aplastic anemia, bone marrow transplant should be pursued in all pediatric patients and in younger adult patients when a matched sibling donor is available. Frontline therapy in older adult patients and in all patients lacking a matched sibling donor involves immunosuppressive therapy (IST) with horse antithymocyte globulin and cyclosporine A. Recent improvements in upfront therapy include encouraging results with upfront closely matched unrelated donor transplants in younger patients and the emerging benefits of eltrombopag combined with initial IST, with randomized studies underway. In the refractory setting, several therapeutic options exist, with improving outcomes of matched unrelated donor and haploidentical bone marrow transplantation as well as the addition of eltrombopag to the non-transplant AA armamentarium. With the recent appreciation of frequent clonal hematopoiesis in AA patients and with the growing use of next-generation sequencing in the clinic, utmost caution should be exercised in interpreting the significance of somatic mutations in AA. Future longitudinal studies of large numbers of patients are needed to determine the prognostic significance of somatic mutations and to guide optimal surveillance and treatment approaches to prevent long term clonal complications.

Corresponding Author: Daria Babushok, M.D. Ph.D., Division of Hematology-Oncology, Department of Medicine, Hospital of the University of Pennsylvania, Philadelphia, Pennsylvania, PCAM 12 South, 3400 Civic Center Blvd, Philadelphia PA 19104, daria.babushok@uphs.upenn.edu, Phone: 215-614-1847, Fax: 215-615-5888.

Compliance with Ethics Guidelines

Conflict of Interest

The authors have no conflicts of interests to disclose.

Human and Animal Rights and Informed Consent

This article does not contain any studies with human or animal subjects performed by any of the authors. 


\section{Keywords}

Aplastic anemia; bone marrow failure; eltrombopag; cyclosporine A; antithymocyte globulin; immunosuppressive therapy; bone marrow transplant; clonal hematopoiesis

\section{Introduction}

Aplastic anemia (AA) is a rare, immune-mediated hematopoietic disorder associated with significant morbidity and mortality. In patients with suspected AA, rapid and accurate diagnosis and concomitant supportive care are critical. Historically, immunosuppressive therapy (IST) and bone marrow transplantation (BMT) in eligible patients have been the mainstay of AA treatment [1]. However, new frontline and salvage therapies are fundamentally changing how we approach therapy of AA, particularly in adult patients [24]. In pediatric patients, new transplant strategies and improvements in supportive care have led to greatly improved outcomes and increasing use of BMT in both upfront and refractory settings [5]. Furthermore, recent recognition of frequent clonal hematopoiesis in AA has changed our understanding of this immune-mediated blood disorder, reframing how we view somatic changes and a diagnosis of myelodysplastic syndrome (MDS) in patients with AA $[6,7]$. Here, we present a comprehensive review of the diagnosis and treatment of AA, focusing on recent studies.

\section{Clinical presentation and epidemiology}

AA should be suspected in patients presenting with pancytopenia and a hypocellular bone marrow. Typical symptoms include fatigue and easy bruising or bleeding; infections may be present, but generally there is no long-standing illness. There is a well-recognized bimodal age distribution with one peak in mid to late childhood and another in the elderly [8]. The estimated annual incidence of AA is $\sim 2$ cases per million in Europe and North America, with a 2-3 fold higher incidence in East Asia [8]. In 10\% of patients, a history of non-viral hepatitis can precede the onset of AA [9]; an uncommon association with eosinophilic fasciitis has also been reported [10]. With rare exceptions, such as chloramphenicol, antiepileptics, and the emerging link to immunotherapies [8, 11], a causal relationship to medications or toxins can be difficult to establish.

\section{Diagnosis and severity stratification}

When AA is suspected, a comprehensive evaluation should be performed rapidly to exclude other mimicking conditions (Figure 1, Table 1). A baseline evaluation requires a full history and physical exam, a complete blood count with differential, a blood smear, a reticulocyte count, and a bone marrow aspirate with a core biopsy, with ancillary studies including cytogenetics and fluorescence in situ hybridization (FISH).

The search for alternative etiologies (Figure 1, Table 1) should focus on ascertainment of drug and toxin exposures, signs and symptoms suggestive of autoimmune or rheumatologic diseases, family and/or personal history suggestive of an inherited BMF disorder, infections, and nutritional deficiencies. Exclusion of inherited BMF is particularly relevant in children 
and younger adults, where, at a minimum, an evaluation should include a detailed family history looking for lifelong cytopenias, congenital anomalies, cancers, and lung and liver pathology; in addition, patients should be screened for Fanconi anemia by testing the patient's lymphocytes for sensitivity to crosslinking agents and for Dyskeratosis congenita by measuring lymphocyte telomere lengths [12]. Lymphocyte telomere lengths may also be low in AA, particularly hepatitis-associated AA, requiring careful interpretation [13]. Additional causes of acquired BMF include autoimmune marrow aplasia due to a clonal Tor NK- large granular lymphocyte (LGL) expansion [14], which can be evaluated by T cell receptor rearrangement studies paired with lymphocyte flow cytometry. Morphologic and cytogenetic analyses are used to evaluate for hypoplastic MDS [15], although limited cellularity frequently precludes informative morphology assessment. Because of their association with acquired AA, detection of a paroxysmal nocturnal hemoglobinuria (PNH) clone (seen in up to $50 \%$ of AA patients) or copy number-neutral loss of heterozygosity of chromosome arm $6 \mathrm{p}$ ( $6 \mathrm{p} \mathrm{CN-LOH}$, seen in about $12 \%$ of AA patients) can be helpful in supporting the diagnosis of AA.

Once the diagnostic evaluation is complete, treatment is guided by the AA severity, established by the Camitta criteria (Figure 1) [16, 17]. For younger patients with severe aplastic anemia (SAA) or very severe aplastic anemia (VSAA), a transplant evaluation should be rapidly initiated. A referral to a tertiary center that specializes in the care of AA patients should be strongly considered.

\section{Supportive Care}

Throughout the diagnostic and treatment process, patients must be provided aggressive supportive care. Generally, restrictive transfusion targets (hemoglobin $>7 \mathrm{~g} / \mathrm{dL}$, platelets > 10,000 cells $/ \mu \mathrm{L}$ ) are preferred, especially in potential transplant candidates, given the risk of alloimmunization and transfusional iron overload [18]. Irradiated blood products should be used to prevent transfusion-associated graft-versus-host disease (GVHD). Because of the high mortality due to invasive mold infections, particularly Aspergillus species, antifungal prophylaxis with voriconazole or posaconazole should be used in patients with severe neutropenia (absolute neutrophil count $<500$ cells $/ \mu \mathrm{L}$ ) [18]. Pneumocystis jirovecii pneumonia (PJP) prophylaxis should be used during the period of lymphopenia following ATG therapy, ideally selecting an alternative to trimethoprim-sulfamethoxazole because of its myelosuppressive effects. Antimicrobial prophylaxis with quinolone antibiotics in patients with VSAA can reduce the risk of gram-negative sepsis, but routine use of prophylactic antibiotics in patients with higher neutrophil counts is not advised in order to limit antibiotic resistance. Because granulocyte-colony-stimulating factor (G-CSF) does not improve overall survival when added to IST $[19,20]$, routine G-CSF use outside of episodes of febrile neutropenia remains controversial [21]. The benefits and risks of vaccines in AA also remain controversial due to the risk of immune activation, with some AA guidelines recommending against vaccinations outside of the post-transplant setting [21]. 


\section{Transplant-based therapies for SAA/VSAA}

\section{Patient selection}

In patients with SAA and VSAA eligible for transplant-based therapy, age remains the major factor predicting survival after matched sibling donor (MSD) allogeneic transplantation. A retrospective analysis from the Center for International Blood and Marrow Transplant Research (CIBMTR) of over 1,300 patients receiving MSD-BMT showed the adjusted 5year overall survival (OS) of 53\% in patients over the age of 40 years, as compared to $82 \%$ for patients under 20 years and $72 \%$ for patients aged 20-40 years [22]. The differences were primarily due to increased GVHD, infections, and delayed platelet recovery in the older cohort. In addition, these patients were more likely to have received prior IST, and/or to have additional comorbidities with poorer performance status and a longer interval between diagnosis and BMT [22]. Although outcomes in older patients transplanted with fludarabine-containing regimens have been more encouraging, these data are limited to retrospective analyses [23]. Thus, the current standard of care for patients older than 40 years is frontline IST, while BMT is the treatment of choice for children and young adults with SAA who have a MSD (Figure 1).

\section{Donor choice}

Historically, frontline transplantation for SAA in patients under 40 years of age has been largely limited to MSD transplants [24, 25]. However, a recent retrospective analysis of approximately 1,450 patients with AA transplanted between 2005 and 2009 showed no significant difference in OS between MSD and matched unrelated donor (MUD) transplant, although rates of acute and chronic GVHD were higher with MUD-BMT [26]. An analysis of 29 pediatric patients treated with Fludarabine/Cyclophosphamide/ATG (FCC) conditioning followed by unrelated donor transplantation showed similar overall and progression-free survival as compared to historical MSD-BMT controls, and superior outcomes compared to IST [5], suggesting that front-line therapy with MUD-BMT may be considered upfront in selected patients under age 20. Randomized trials are underway to compare outcomes of upfront MUD-BMT versus IST in pediatric patients without a matched sibling donor (Pediatric Blood and Marrow Transplant Consortium and the North American Pediatric Aplastic Anemia Consortium); studies exploring frontline MUD-BMT in adults under 40 are also ongoing (Blood and Marrow Transplant Clinical Trials Network). Pending these prospective studies, IST remains the standard upfront AA therapy in patients without MSD [26, 5].

The outcomes of mismatched or haploidentical donor transplantation in AA have also improved. In a prospective multicenter study of 101 AA patients receiving haploidentical transplants in China, 94\% of patients achieved successful engraftment with 3-year overall and failure free survival of $89 \%$ and $86 \%$, respectively [27]. A registry-based comparison of upfront haploidentical and MSD transplantation in 158 consecutive SAA patients in China have shown similar high rates of engraftment and OS, but significantly higher rates of grade III-IV acute GVHD (10\% versus 1.5\%) and chronic GVHD (31\% versus 4.4\%) for haploidentical transplants [28]. A more recent study of 16 patients receiving haploidentical or unrelated donor transplants with post-transplant cyclophosphamide showed encouraging 
results with 100\% engraftment and no instances of grade 3 or higher GVHD [29]. Novel approaches including co-infusion of mesenchymal stem cells [30] and selective T cell Receptor $\alpha \beta$ depletion [31] are being explored.

\section{Graft source}

Bone marrow grafts have been shown to produce superior OS compared to peripheral blood stem cell (PBSC) grafts in both pediatric [32] and adult [33] AA patients, due to lower rates of GVHD. More recent efforts to improve outcomes with PBSC showed encouraging results with partial $\mathrm{T}$ cell depletion [34]; larger randomized prospective studies are needed to confirm the efficacy and safety of this approach.

\section{Conditioning Regimens}

The standard conditioning regimen for MSD-BMT in younger patients is $200 \mathrm{mg} / \mathrm{kg}$ cyclophosphamide with antithymocyte globulin (ATG), with three-year survival rates of $92 \%$ [35]. However, subsequent studies in older transplant recipients (age > 30) did not show a survival benefit when compared to IST [36]. To reduce toxicity in older patients, newer regimens have incorporated fludarabine with lower-dose cyclophosphamide and with ATG (FCA) or alemtuzumab (FCC), with improved OS [37-39]. A CIBMTR analysis of 833 AA bone marrow transplants evaluated the role of ATG source on transplant outcomes, and demonstrated that rabbit ATG (Thymoglobulin, Sanofi, France) results in lower rates of acute and chronic GVHD for MSD transplants, improves survival, and lowers rates of acute GVHD for MUD transplants [40]. Conditioning for MUD and haploidentical transplants also includes $200 \mathrm{cGy}$ total body irradiation [41].

\section{Non-transplant therapy of AA}

\section{Immunosuppression}

For patients older than 40 years with newly-diagnosed SAA/VSAA or younger patients without an MSD, immunosuppression with ATG and cyclosporine A (CsA) continues to be the recommended frontline therapy (Figure 1) [42], offering outcomes comparable to allogeneic BMT with reduced morbidity in older patients [43, 44]. Horse ATG is the recommended ATG source, based on a randomized-controlled trial of 120 patients showing a superior overall response (68\% compared to $37 \%$ ) and OS (96\% compared to $76 \%$ ) for horse ATG-based IST compared to rabbit ATG-based IST [45].

\section{Role of Eltrombopag in Frontline Therapy}

One of the most promising recent treatments for AA is the oral thrombopoietin (TPO) receptor agonist eltrombopag, previously approved for treatment of chronic idiopathic thrombocytopenic purpura [46]. Studies in mouse models showed that signaling via the TPO receptor c-mpl is necessary for hematopoietic stem cell maintenance and downstream expansion and differentiation [47, 48]. Interestingly, patients with congenital amegakaryocytic thrombocytopenia who have mutations in c-mpl can progress to aplastic anemia, suggesting that a deficiency in TPO signaling may play a role in AA pathogenesis [49]. Based on these studies, eltrombopag was initially tested as monotherapy in a Phase 2 study of 43 patients with relapsed/refractory SAA with persistent thrombocytopenia 
following IST [2, 3]. The overall response rate after 3-4 months of therapy was $40 \%$ (17 of 43). Remarkably, one patient achieved a trilineage response, and 8 patients had neutrophil responses including 4 with severe neutropenia. With long-term treatment, 7 patients achieved trilineage responses. An early signal of increased clonal evolution in this high-risk population was also noted with $19 \%$ (8 of 43 ) patients developing cytogenetic abnormalities during follow-up [2,3].

Based on these encouraging data, a phase $1 / 2$ study evaluated whether the addition of eltrombopag to frontline IST can further improve patient outcomes [4]. 92 patients were assigned to receive daily eltrombopag in addition to horse ATG and CsA in three separate cohorts starting eltrombopag at either day 0 or day 14 and continuing for 3 or 6 months. Because of the concern for karyotypic evolution [2,3], patients with cytogenetic abnormalities were excluded. The overall response rate at 6 months in the three cohorts ranged between $80-94 \%$, as compared to $66 \%$ in the composite historical cohort of 102 patients $[50,45]$. There was also an encouraging improvement in the rate of complete response, at 36\% with eltrombopag as compared to a historical estimate of $10 \%$ with standard IST. During an initial phase of the study CsA was discontinued at 6 months, with a relapse rate of $32 \%-54 \%$, leading to a protocol amendment to extend CsA duration to 2 years [4]. Encouragingly, the rates of chromosomal aberrations were similar to those in historical controls, $\sim 8 \%$ at 2 years of follow-up [4]. Several prospective randomized trials combining eltrombopag therapy with IST are underway to confirm these findings and to better assess long-term efficacy and safety, particularly clonal evolution (Table 2). However, given these encouraging early results and low observed toxicity, we believe that in selected newly diagnosed SAA/VSAA patients without pre-existing karyotypic abnormalities, addition of six months of eltrombopag to upfront standard IST should be considered.

\section{Cyclosporine Maintenance and Taper}

Although there are no definitive data on the optimal duration of CsA, it is clear that early discontinuation leads to a high rate of early relapse. An 11-year follow-up of a randomized trial of horse ATG with or without CsA showed that CsA maintenance delays relapses. 26\% of patients required CsA for greater than 6 months due to recurrent cytopenias on discontinuation [43]. Follow-up of two National Institutes of Health cohorts totaling 102 patients treated with standard IST for whom CsA taper was started at 6 months showed a cumulative relapse rate of $33 \%$ at 5 years of follow-up, with a median time to relapse of 2 years [51]. Compared to historical cohorts that discontinued CsA at 6 months, a tapering regimen delayed relapse by approximately 1 year [51]. The high relapse rates of 32\%-54\% in the recent study of eltrombopag added to upfront IST were also attributed to early CsA discontinuation, and were improved with extending CsA to a 2 year maintenance [4]. There are limited data on the rate of CsA taper, although an analysis of 33 pediatric AA patients suggested that a slower taper of $<0.3 \mathrm{mg} / \mathrm{kg} / \mathrm{month}$ may lead to fewer relapses [52]. Putting these data together, our practice (Figure 1) is to continue full dose CsA, targeting therapeutic CsA trough of 200-300 mcg/L, for approximately 12 months after horse ATG therapy and until achievement of stable and maximally-improved blood counts, at which time we initiate a slow taper with no more than $10 \%$ dose reduction at a time over the course of approximately one year. 


\section{Treatment of nonsevere aplastic anemia (NSAA)}

Unlike the fairly defined guidelines for frontline treatment of SAA/VSAA (Figure 1), the approach to nonsevere aplastic anemia (NSAA) is more nuanced. The natural history of patients with NSAA has been evaluated in several retrospective analyses, showing progression of cytopenias in $20-67 \%$ of NSAA patients [53-56]. Interestingly, NSAA patients managed in more recent years (1997-2002) appear to have worse outcomes with a 56\% 10-year survival as compared to 70\% in NSAA patients treated between 1991-1996; this was associated with a significantly longer interval from diagnosis to treatment in the more recent cohort (52 versus 102 days) [57]. Expert AA guidelines recommend treating NSAA patients if they have transfusion dependence or neutropenia [21]. A prospective randomized study compared horse ATG and CsA to CsA monotherapy in 114 NSAA patients, showing significantly higher overall response (74\% versus $46 \%$ ) in the ATG and CsA arm [58]. Transfusion independence was achieved in $90 \%$ of ATG/CsA-treated patients compared to only $67 \%$ of patients receiving CsA alone; 5-year OS was equivalent in both groups [58]. The outcomes of a recent cohort of 95 Japanese NSAA patients treated with horse ATG and CsA were less encouraging, showing a lower 6-month response rate of 55\% and a 10 -year failure free survival of $44 \%$, with the majority of patients needing second- and third-line therapies. The median time to initial treatment was 47 days [59].

More recently, eltrombopag has been proposed as a potential option for NSAA patients, with a number of ongoing studies studying the safety and efficacy of eltrombopag in combination with CsA in NSAA (Table 2) [60]. Given the excellent tolerability and efficacy of eltrombopag in the relapsed/refractory and first-line SAA/VSAA settings (Table 2) [2-4], we anticipate that eltrombopag-containing regimens would be similarly beneficial in NSAA and may allow for improved outcomes with lower toxicities in this population.

Several other treatments have been investigated in NSAA; however, to date, none have been demonstrated to be superior to standard IST. In 45 patients with NSAA treated with a recombinant humanized anti-IL2 receptor antibody daclizumab, $42 \%$ achieved a hematologic response at 3 months [61], although only $25 \%$ achieved transfusion independence at $\sim 5$ years of follow-up [62]. An antihelminthic agent levamisole, associated with immunomodulatory activity, was tested in combination with CsA in 118 Chinese patients with NSAA; the study found a nearly $100 \%$ overall response rate in 42 patients with newly-diagnosed NSAA and 87\% overall response rate in chronic NSAA [63], suggesting that CsA combined with levamisole may be a promising therapy to be evaluated in future randomized studies.

\section{Clonal evolution}

The improvement in long-term survival of AA patients led to an increased appreciation of the long-term clonal sequelae of AA. 15\% of AA patients treated with IST go on to develop the late complications of MDS and acute myeloid leukemia (AML) [64, 65, 43]. Approximately $10 \%$ of AA patients (range 3-26\%) develop cytogenetic changes during the course of their disease (reviewed in [7]), most commonly monosomy 7/del (7q) and trisomy 8 , as well as del (13q), and trisomies of chromosomes 6,15 and 21. In the context of AA, 
monosomy 7 has been found to correlate with a poor prognosis, including a worse response to IST and increased progression to MDS, while del (13q) and trisomy 8 are associated with an improved response to IST and a better prognosis (reviewed in [6, 7]).

Newer techniques combining single nucleotide polymorphism arrays (SNP-A) and nextgeneration sequencing (NGS) have allowed to more precisely evaluate clonal hematopoiesis in AA. The majority of AA patients, including over $60 \%$ of children with AA, develop clonal genetic changes $[66,67]$. Several recent reviews comprehensively addressed this topic $[6,7,68]$. The most common clonal abnormality in AA is the development of PNH clones, which can be detected by flow cytometry as cells lacking glycophophatidyl-inositol-linked proteins due to a somatic mutation in the PIGA gene $[69,70]$, found in up to $50 \%$ of AA patients. The second most common is somatic loss of human leukocyte antigen (HLA) loci, that are detected as either regions of acquired $6 \mathrm{p} \mathrm{CN-LOH}$ or as inactivating mutations in HLA class I genes in approximately $17 \%$ of AA patients [71-74]. Both PNH clones and HLA loss are hypothesized to occur due to immune escape, and, if present, can be helpful in corroborating a diagnosis of AA. The presence of even a subclinical PNH clone has been found to correlate with an improved response to IST [75-79, 70]. In contrast to PNH, the prognostic impact of somatic HLA loss is less clear [71,72], with emerging data suggesting that HLA loss may be best viewed as a marker of a higher immune pathogenicity of a patient's inherited HLA alleles [74, 73].

Using targeted NGS of genes recurrently mutated in hematologic malignancies, several groups identified somatic mutations in MDS-associated genes in AA, detected in up to a third of adult AA patients [80-83, 66]. The most commonly mutated malignancy-associated genes in AA are $A S X L 1, B C O R / B C O R L 1$, and DNMT3A [66, 81, 82]. The prognostic implications of somatic mutations in MDS-associated genes are not clear, due to the lack of prospective, long-term studies of large numbers of patients carrying these mutations. Nevertheless, available data suggest that mutations in BCOR and BCORL1 may be predictive of an improved response to IST [66], and together with mutations in PIGA, comprise a group with "favorable" prognosis [66]. In the comprehensive study of clonal hematopoiesis in AA by Yoshizato and colleagues, no other genes were identified to have prognostic significance individually, perhaps due to the limited statistical power, although several genes (DNMT3A, ASXL1, TP53, RUNX1, and CSMD1) were associated with worse OS when analyzed in aggregate [66]. Putting together the available data, it is clear that the majority of pediatric and adult AA patients develop clonal hematopoiesis, with a large fraction of adult AA patients having detectable somatic mutations in genes that are frequently altered in aging and MDS. However, only $~ 15 \%$ of AA patients progress to the late complications of MDS and leukemia after 10 years of follow-up [64]. Thus, in the absence of prospective longitudinal studies evaluating the prognosis of AA patients carrying specific MDS-associated somatic mutations, we advise caution when factoring the presence of somatic mutations into therapeutic decisions in this patient population.

\section{Salvage therapy for relapsed and refractory aplastic anemia}

Despite overall improvement in AA outcomes, $\sim 33-35 \%$ of patients who initially respond to IST will relapse during or after CsA taper, while another $35 \%$ will be refractory to frontline 
IST [45, 1]. Most patients ( $\sim 60-68 \%)$ who relapse following an initial response to IST can be salvaged with full-dose CsA monotherapy and/or a second course of IST with rabbit ATG and CsA $[84,52,85,42,86]$ or transplant. Alternatives to ATG and CsA in relapsed disease include alemtuzumab, which, in a single-arm prospective study of 25 patients with relapsed AA, was shown to produce a hematologic response in $56 \%$ of patients, with $86 \% 3$-year survival [87]. Because most patients will respond to a second round of IST [84], in adults, transplant therapies are usually reserved for relapsed patients who failed an attempt of salvage with a second course of immunosuppression, while excellent outcomes in children with salvage BMT after IST failure make MUD-BMT a reasonable second-line option [88].

Compared to relapsed AA patients who previously responded to IST, patients with primary refractory AA have worse outcomes, and only $\sim 30 \%$ of refractory AA patients can be salvaged with rabbit ATG and CsA [84]. The failure-free survival in refractory pediatric patients treated with second-line IST can be as poor as $9.5 \%$, as compared to $>80 \%$ for salvage SCT [89]. Thus, refractory AA patients should be evaluated for salvage allogeneic transplant options, which may include HLA identical sibling, matched unrelated, or haploidentical bone marrow transplantation, depending on donor availability. Among nontransplant therapies, eltrombopag has hematologic response rates of $~ 40 \%$ in refractory AA, including some trilineage responses, and represents an important option, particularly for older adults or patients who are poor transplant candidates [2, 3].

There are several additional second- and third-line treatment options for refractory AA, of which danazol and alemtuzumab are more commonly used. In 48 patients with refractory AA randomized to receive alemtuzumab versus rabbit ATG with CsA, alemtuzumab was comparable to rabbit ATG arm, with a hematologic response of $37 \%$ and a 3-year survival of $83 \%$ [87]. Although androgen therapy has not been found to improve survival in combination with first-line IST [90, 91], a study of 16 refractory AA patients suggests that androgens may be helpful, particularly in female patients [92]. Cyclophosphamide in moderate to high doses also has efficacy in refractory AA [93-95], but significant toxicity with prolonged neutropenia and high rates of infectious have largely limited its use [96, 97].

\section{Summary}

AA is a rare, life-threatening, BMF syndrome that requires a systematic and timely approach to diagnosis and treatment. For a younger patient with a MSD, allogeneic BMT remains the standard frontline therapy, while other patients should receive frontline immunosuppression with horse ATG and CsA. Emerging data suggest that addition of eltrombopag to frontline IST can further improve outcomes and that outcomes following upfront MUD BMT may now be equivalent to MSD-BMT, at least in pediatric patients. Long-term prospective studies are underway to confirm the safety and efficacy of these approaches. As the outcomes of MUD and haploidentical transplantation improve and with emergence of eltrombopag as an effective agent in refractory AA, we expect that outcomes of patients with refractory AA will improve. Finally, with the recent findings of frequent clonal hematopoiesis in the majority of AA patients, utmost caution should be exercised in the interpretation of molecular changes which are common in this patient population and, in the absence of longterm prospective studies, do not have well-defined prognostic implications. 


\section{Acknowledgments}

This work was supported by NHLBI T32 HL007439-38 grant to S.A.P, NHLBI K08 HL122306 to T.O., and NHLBI K08 HL132101-01 and AA \& MDS International Foundation Research Grant to D.V.B, and and NIH/ NIDDK R24DK103001 for Penn/CHOP AA studies.

\section{References and Recommended Reading}

Papers of particular interest, published recently, have been highlighted as:

- Of importance

•• Of major importance

1. Scheinberg P, Young NS. How I treat acquired aplastic anemia. Blood. 2012; 120(6):1185-96. DOI: 10.1182/blood-2011-12-274019 [PubMed: 22517900]

2. Olnes MJ, Scheinberg P, Calvo KR, Desmond R, Tang Y, Dumitriu B, et al. Eltrombopag and improved hematopoiesis in refractory aplastic anemia. N Engl J Med. 2012; 367(1):11-9. DOI: 10.1056/NEJMoa1200931 [PubMed: 22762314]

••3. Desmond R, Townsley DM, Dumitriu B, Olnes MJ, Scheinberg P, Bevans M, et al. Eltrombopag restores trilineage hematopoiesis in refractory severe aplastic anemia that can be sustained on discontinuation of drug. Blood. 2014; 123(12):1818-25. doi:10.1182/blood-2013-10-534743. A follow-up of a phase 2 study of eltrombopag monotherapy in patients with refractory SAA showing an overall response of $40 \%$, with a subset of patients achieving trilineage hematopoietic responses. [PubMed: 24345753]

••4. Townsley DM, Scheinberg P, Winkler T, Desmond R, Dumitriu B, Rios O, et al. Eltrombopag Added to Standard Immunosuppression for Aplastic Anemia. N Engl J Med. 2017; 376(16): 1540-50. doi:10.1056/NEJMoa1613878. A prospective phase 1-2 study of immunosuppressive therapy plus eltrombopag in newly-diagnosed SAA showing that addition of eltrombopag improves hematologic response as compared to historical IST controls. [PubMed: 28423296]

-5. Dufour C, Veys P, Carraro E, Bhatnagar N, Pillon M, Wynn R, et al. Similar outcome of upfrontunrelated and matched sibling stem cell transplantation in idiopathic paediatric aplastic anaemia. A study on behalf of the UK Paediatric BMT Working Party, Paediatric Diseases Working Party and Severe Aplastic Anaemia Working Party of EBMT. Br J Haematol. 2015; 171(4):585-94. doi:10.1111/bjh.13614. A retrospective analysis of 29 consecutive children who underwent unrelated donor transplantation with Fludarabine/Cyclophosphamide/Alemtuzumab (FCC) conditioning in an upfront setting, which showed outcomes similar to historical controls treated with matched sibling donor transplantation and superior to IST and to unrelated donor transplant after IST failure, suggesting that front-line therapy with unrelated donor BMT may be considered in selected pediatric patients without a matched sibling donor. [PubMed: 26223288]

6. Ogawa S. Clonal hematopoiesis in acquired aplastic anemia. Blood. 2016; 128(3):337-47. DOI: 10.1182/blood-2016-01-636381 [PubMed: 27121470]

7. Stanley N, Olson TS, Babushok DV. Recent advances in understanding clonal haematopoiesis in aplastic anaemia. Br J Haematol. 2017; 177(4):509-25. DOI: 10.1111/bjh.14510 [PubMed: 28107566]

8. Young NS, Kaufman DW. The epidemiology of acquired aplastic anemia. Haematologica. 2008; 93(4):489-92. DOI: 10.3324/haematol.12855 [PubMed: 18379007]

9. Brown KE, Tisdale J, Barrett AJ, Dunbar CE, Young NS. Hepatitis-associated aplastic anemia. N Engl J Med. 1997; 336(15):1059-64. DOI: 10.1056/NEJM199704103361504 [PubMed: 9091802]

10. Kim SW, Rice L, Champlin R, Udden MM. Aplastic anemia in eosinophilic fasciitis: responses to immunosuppression and marrow transplantation. Haematologia (Budap). 1997; 28(3):131-7. [PubMed: 9283913]

11. Helgadottir H, Kis L, Ljungman P, Larkin J, Kefford R, Ascierto PA, et al. Lethal aplastic anemia caused by dual immune checkpoint blockade in metastatic melanoma. Ann Oncol. 2017; doi: 10.1093/annonc/mdx177 
12. Wilson DB, Link DC, Mason PJ, Bessler M. Inherited bone marrow failure syndromes in adolescents and young adults. Ann Med. 2014; 46(6):353-63. DOI: 10.3109/07853890.2014.915579 [PubMed: 24888387]

13. Babushok DV, Grignon AL, Li Y, Atienza J, Xie HM, Lam HS, et al. Disrupted lymphocyte homeostasis in hepatitis-associated acquired aplastic anemia is associated with short telomeres. Am J Hematol. 2016; 91(2):243-7. DOI: 10.1002/ajh.24256 [PubMed: 26615915]

14. Jerez A, Clemente MJ, Makishima H, Rajala H, Gomez-Segui I, Olson T, et al. STAT3 mutations indicate the presence of subclinical T-cell clones in a subset of aplastic anemia and myelodysplastic syndrome patients. Blood. 2013; 122(14):2453-9. doi:blood-2013-04-494930 [pii] 10.1182/blood-2013-04-494930. [PubMed: 23926297]

15. Nakao S, Gale RP. Are mild/moderate acquired idiopathic aplastic anaemia and low-risk myelodysplastic syndrome one or two diseases or both and how should it/they be treated? Leukemia. 2016; 30(11):2127-30. DOI: 10.1038/leu.2016.206 [PubMed: 27585953]

16. Camitta BM. Pathogenesis and treatment of aplastic anemia. Rinsho Ketsueki. 1984; 25(4):459-69. [PubMed: 6381789]

17. Rovo A, Tichelli A, Dufour C. Diagnosis of acquired aplastic anemia. Bone Marrow Transplant. 2013; 48(2):162-7. DOI: 10.1038/bmt.2012.230 [PubMed: 23165495]

18. Hochsmann B, Moicean A, Risitano A, Ljungman P, Schrezenmeier H. Supportive care in severe and very severe aplastic anemia. Bone Marrow Transplant. 2013; 48(2):168-73. DOI: 10.1038/ bmt.2012.220 [PubMed: 23208312]

19. Teramura M, Kimura A, Iwase S, Yonemura Y, Nakao S, Urabe A, et al. Treatment of severe aplastic anemia with antithymocyte globulin and cyclosporin A with or without G-CSF in adults: a multicenter randomized study in Japan. Blood. 2007; 110(6):1756-61. DOI: 10.1182/ blood-2006-11-050526 [PubMed: 17526862]

20. Tichelli A, Schrezenmeier H, Socie G, Marsh J, Bacigalupo A, Duhrsen U, et al. A randomized controlled study in patients with newly diagnosed severe aplastic anemia receiving antithymocyte globulin (ATG), cyclosporine, with or without G-CSF: a study of the SAA Working Party of the European Group for Blood and Marrow Transplantation. Blood. 2011; 117(17):4434-41. DOI: 10.1182/blood-2010-08-304071 [PubMed: 21233311]

-21. Killick SB, Bown N, Cavenagh J, Dokal I, Foukaneli T, Hill A, et al. Guidelines for the diagnosis and management of adult aplastic anaemia. Br J Haematol. 2016; 172(2):187-207. doi:10.1111/ bjh.13853. The 2015 update of expert AA guidelines from the British Society for Haematology (BSH). [PubMed: 26568159]

22. Gupta V, Eapen M, Brazauskas R, Carreras J, Aljurf M, Gale RP, et al. Impact of age on outcomes after bone marrow transplantation for acquired aplastic anemia using HLA-matched sibling donors. Haematologica. 2010; 95(12):2119-25. DOI: 10.3324/haematol.2010.026682 [PubMed: 20851870]

23. Shin SH, Jeon YW, Yoon JH, Yahng SA, Lee SE, Cho BS, et al. Comparable outcomes between younger (40 years) and older ( $>40$ years) adult patients with severe aplastic anemia after HLAmatched sibling stem cell transplantation using fludarabine-based conditioning. Bone Marrow Transplant. 2016; 51(11):1456-63. DOI: 10.1038/bmt.2016.171 [PubMed: 27348538]

24. Bacigalupo A, Brand R, Oneto R, Bruno B, Socie G, Passweg J, et al. Treatment of acquired severe aplastic anemia: bone marrow transplantation compared with immunosuppressive therapy--The European Group for Blood and Marrow Transplantation experience. Semin Hematol. 2000; 37(1): 69-80. [PubMed: 10676912]

25. Yoshida N, Kobayashi R, Yabe H, Kosaka Y, Yagasaki H, Watanabe K, et al. First-line treatment for severe aplastic anemia in children: bone marrow transplantation from a matched family donor versus immunosuppressive therapy. Haematologica. 2014; 99(12):1784-91. DOI: 10.3324/ haematol.2014.109355 [PubMed: 25193958]

-26. Bacigalupo A, Socie G, Hamladji RM, Aljurf M, Maschan A, Kyrcz-Krzemien S, et al. Current outcome of HLA identical sibling versus unrelated donor transplants in severe aplastic anemia: an EBMT analysis. Haematologica. 2015; 100(5):696-702. doi:10.3324/haematol.2014.115345. A retrospective analysis of AA patients who underwent transplant between 2005 and 2009 based on the EBMT registry showing that unrelated donor transplants are not statistically inferior to 
sibling transplants, although they have a higher risk of GVHD. The strongest predictor of survival continues to be the use of peripheral blood stem cell graft. [PubMed: 25616576]

27. Xu LP, Wang SQ, Wu DP, Wang JM, Gao SJ, Jiang M, et al. Haplo-identical transplantation for acquired severe aplastic anaemia in a multicentre prospective study. Br J Haematol. 2016; 175(2): 265-74. DOI: 10.1111/bjh.14225 [PubMed: 27352174]

28. Xu LP, Jin S, Wang SQ, Xia LH, Bai H, Gao SJ, et al. Upfront haploidentical transplant for acquired severe aplastic anemia: registry-based comparison with matched related transplant. J Hematol Oncol. 2017; 10(1):25.doi: 10.1186/s13045-017-0398-y [PubMed: 28107815]

29. DeZern AE, Zahurak M, Symons H, Cooke K, Jones RJ, Brodsky RA. Alternative Donor Transplantation with High-Dose Post-Transplantation Cyclophosphamide for Refractory Severe Aplastic Anemia. Biol Blood Marrow Transplant. 2017; 23(3):498-504. DOI: 10.1016/j.bbmt. 2016.12.628 [PubMed: 28013015]

30. Liu Z, Zhang Y, Xiao H, Yao Z, Zhang H, Liu Q, et al. Cotransplantation of bone marrow-derived mesenchymal stem cells in haploidentical hematopoietic stem cell transplantation in patients with severe aplastic anemia: an interim summary for a multicenter phase II trial results. Bone Marrow Transplant. 2017; 52(5):704-10. DOI: 10.1038/bmt.2016.347 [PubMed: 28067873]

31. Bertaina A, Merli P, Rutella S, Pagliara D, Bernardo ME, Masetti R, et al. HLA-haploidentical stem cell transplantation after removal of alphabeta+ T and B cells in children with nonmalignant disorders. Blood. 2014; 124(5):822-6. DOI: 10.1182/blood-2014-03-563817 [PubMed: 24869942]

32. Schrezenmeier H, Passweg JR, Marsh JC, Bacigalupo A, Bredeson CN, Bullorsky E, et al. Worse outcome and more chronic GVHD with peripheral blood progenitor cells than bone marrow in HLA-matched sibling donor transplants for young patients with severe acquired aplastic anemia. Blood. 2007; 110(4):1397-400. DOI: 10.1182/blood-2007-03-081596 [PubMed: 17475907]

33. Bacigalupo A, Socie G, Schrezenmeier H, Tichelli A, Locasciulli A, Fuehrer M, et al. Bone marrow versus peripheral blood as the stem cell source for sibling transplants in acquired aplastic anemia: survival advantage for bone marrow in all age groups. Haematologica. 2012; 97(8):11428. DOI: 10.3324/haematol.2011.054841 [PubMed: 22315497]

34. Purev E, Tian X, Aue G, Pantin J, Vo P, Shalabi R, et al. Allogeneic transplantation using CD34+ selected peripheral blood progenitor cells combined with non-mobilized donor T cells for refractory severe aplastic anaemia. Br J Haematol. 2017; 176(6):950-60. DOI: 10.1111/bjh.14448 [PubMed: 28169418]

35. Storb R, Etzioni R, Anasetti C, Appelbaum FR, Buckner CD, Bensinger W, et al. Cyclophosphamide combined with antithymocyte globulin in preparation for allogeneic marrow transplants in patients with aplastic anemia. Blood. 1994; 84(3):941-9. [PubMed: 8043876]

36. Doney K, Leisenring W, Storb R, Appelbaum FR. Primary treatment of acquired aplastic anemia: outcomes with bone marrow transplantation and immunosuppressive therapy. Seattle Bone Marrow Transplant Team. Ann Intern Med. 1997; 126(2):107-15. [PubMed: 9005744]

37. Grimaldi F, Potter V, Perez-Abellan P, Veluchamy JP, Atif M, Grain R, et al. Mixed T Cell Chimerism After Allogeneic Hematopoietic Stem Cell Transplantation for Severe Aplastic Anemia Using an Alemtuzumab-Containing Regimen Is Shaped by Persistence of Recipient CD8 T Cells. Biol Blood Marrow Transplant. 2017; 23(2):293-9. DOI: 10.1016/j.bbmt.2016.11.003 [PubMed: 27816648]

38. Maury S, Bacigalupo A, Anderlini P, Aljurf M, Marsh J, Socie G, et al. Improved outcome of patients older than 30 years receiving HLA-identical sibling hematopoietic stem cell transplantation for severe acquired aplastic anemia using fludarabine-based conditioning: a comparison with conventional conditioning regimen. Haematologica. 2009; 94(9):1312-5. DOI: 10.3324/haematol.2009.006916 [PubMed: 19734425]

39. Bacigalupo A. How I treat acquired aplastic anemia. Blood. 2017; 129(11):1428-36. DOI: 10.1182/blood-2016-08-693481 [PubMed: 28096088]

-40. Kekre N, Zhang Y, Zhang MJ, Carreras J, Ahmed P, Anderlini P, et al. Effect of antithymocyte globulin source on outcomes of bone marrow transplantation for severe aplastic anemia. Haematologica. 2017; 102(7):1291-8. doi:10.3324/haematol.2017.164459. A retrospective analysis of 833 patients who underwent bone marrow transplant for severe AA, showing that conditioning regimens with rabbit ATG achieve lower rates of GVHD and improved survival as compared to horse ATG. [PubMed: 28341733] 
41. Tolar J, Deeg HJ, Arai S, Horwitz M, Antin JH, McCarty JM, et al. Fludarabine-based conditioning for marrow transplantation from unrelated donors in severe aplastic anemia: early results of a cyclophosphamide dose deescalation study show life-threatening adverse events at predefined cyclophosphamide dose levels. Biol Blood Marrow Transplant. 2012; 18(7):1007-11. DOI: 10.1016/j.bbmt.2012.04.014 [PubMed: 22546497]

42. Frickhofen N, Kaltwasser JP, Schrezenmeier H, Raghavachar A, Vogt HG, Herrmann F, et al. Treatment of aplastic anemia with antilymphocyte globulin and methylprednisolone with or without cyclosporine. The German Aplastic Anemia Study Group. N Engl J Med. 1991; 324(19): 1297-304. DOI: 10.1056/nejm199105093241901 [PubMed: 2017225]

43. Frickhofen N, Heimpel H, Kaltwasser JP, Schrezenmeier H. German Aplastic Anemia Study G. Antithymocyte globulin with or without cyclosporin A: 11-year follow-up of a randomized trial comparing treatments of aplastic anemia. Blood. 2003; 101(4):1236-42. DOI: 10.1182/ blood-2002-04-1134 [PubMed: 12393680]

44. Bacigalupo A, Bruno B, Saracco P, Di Bona E, Locasciulli A, Locatelli F, et al. Antilymphocyte globulin, cyclosporine, prednisolone, and granulocyte colony-stimulating factor for severe aplastic anemia: an update of the GITMO/EBMT study on 100 patients. European Group for Blood and Marrow Transplantation (EBMT) Working Party on Severe Aplastic Anemia and the Gruppo Italiano Trapianti di Midolio Osseo (GITMO). Blood. 2000; 95(6):1931-4. [PubMed: 10706857]

45. Scheinberg P, Nunez O, Weinstein B, Biancotto A, Wu CO, Young NS. Horse versus rabbit antithymocyte globulin in acquired aplastic anemia. N Engl J Med. 2011; 365(5):430-8. DOI: 10.1056/NEJMoa1103975 [PubMed: 21812672]

46. Bussel JB, Cheng G, Saleh MN, Psaila B, Kovaleva L, Meddeb B, et al. Eltrombopag for the treatment of chronic idiopathic thrombocytopenic purpura. N Engl J Med. 2007; 357(22):2237-47. DOI: 10.1056/NEJMoa073275 [PubMed: 18046028]

47. Alexander WS, Roberts AW, Nicola NA, Li R, Metcalf D. Deficiencies in progenitor cells of multiple hematopoietic lineages and defective megakaryocytopoiesis in mice lacking the thrombopoietic receptor c-Mpl. Blood. 1996; 87(6):2162-70. [PubMed: 8630375]

48. Kimura S, Roberts AW, Metcalf D, Alexander WS. Hematopoietic stem cell deficiencies in mice lacking c-Mpl, the receptor for thrombopoietin. Proc Natl Acad Sci U S A. 1998; 95(3):1195-200. [PubMed: 9448308]

49. Ballmaier M, Germeshausen M, Krukemeier S, Welte K. Thrombopoietin is essential for the maintenance of normal hematopoiesis in humans: development of aplastic anemia in patients with congenital amegakaryocytic thrombocytopenia. Ann N Y Acad Sci. 2003; 996:17-25. [PubMed: 12799278]

50. Scheinberg P, Wu CO, Nunez O, Scheinberg P, Boss C, Sloand EM, et al. Treatment of severe aplastic anemia with a combination of horse antithymocyte globulin and cyclosporine, with or without sirolimus: a prospective randomized study. Haematologica. 2009; 94(3):348-54. DOI: 10.3324/haematol.13829 [PubMed: 19181786]

-51. Scheinberg P, Rios O, Scheinberg P, Weinstein B, Wu CO, Young NS. Prolonged cyclosporine administration after antithymocyte globulin delays but does not prevent relapse in severe aplastic anemia. Am J Hematol. 2014; 89(6):571-4. A comparison of outcomes of NIH AA cohorts who were treated with IST followed by an 18-month cyclosporine A taper starting 6 months after IST, as compared to historical controls who discontinued cyclosporine A 6 months after IST, showed that cyclosporine A taper delayed relapse by approximately one year, but did not eliminate relapses. [PubMed: 24971433]

52. Saracco P, Quarello P, Iori AP, Zecca M, Longoni D, Svahn J, et al. Cyclosporin A response and dependence in children with acquired aplastic anaemia: a multicentre retrospective study with long-term observation follow-up. Br J Haematol. 2008; 140(2):197-205. DOI: 10.1111/j. 1365-2141.2007.06903.x [PubMed: 18173756]

53. Kwon JH, Kim I, Lee YG, Koh Y, Park HC, Song EY, et al. Clinical course of non-severe aplastic anemia in adults. Int J Hematol. 2010; 91(5):770-5. DOI: 10.1007/s12185-010-0601-1 [PubMed: 20524094]

54. Howard SC, Naidu PE, Hu XJ, Jeng MR, Rodriguez-Galindo C, Rieman MD, et al. Natural history of moderate aplastic anemia in children. Pediatr Blood Cancer. 2004; 43(5):545-51. DOI: 10.1002/ pbc.20131 [PubMed: 15382271] 
55. Brock K, Goldenberg N, Graham DK, Liang X, Hays T. Moderate aplastic anemia in children: preliminary outcomes for treatment versus observation from a single-institutional experience. $\mathrm{J}$ Pediatr Hematol Oncol. 2013; 35(2):148-52. DOI: 10.1097/MPH.0b013e3182755f36 [PubMed: 23128338]

56. Nishio N, Yagasaki H, Takahashi Y, Muramatsu H, Hama A, Yoshida N, et al. Natural history of transfusion-independent non-severe aplastic anemia in children. Int J Hematol. 2009; 89(4):40913. DOI: 10.1007/s12185-009-0302-9 [PubMed: 19343478]

57. Locasciulli A, Oneto R, Bacigalupo A, Socie G, Korthof E, Bekassy A, et al. Outcome of patients with acquired aplastic anemia given first line bone marrow transplantation or immunosuppressive treatment in the last decade: a report from the European Group for Blood and Marrow Transplantation (EBMT). Haematologica. 2007; 92(1):11-8. [PubMed: 17229630]

58. Marsh J, Schrezenmeier H, Marin P, Ilhan O, Ljungman P, McCann S, et al. Prospective randomized multicenter study comparing cyclosporin alone versus the combination of antithymocyte globulin and cyclosporin for treatment of patients with nonsevere aplastic anemia: a report from the European Blood and Marrow Transplant (EBMT) Severe Aplastic Anaemia Working Party. Blood. 1999; 93(7):2191-5. [PubMed: 10090926]

59. Nishikawa E, Yagasaki H, Hama A, Yabe H, Ohara A, Kosaka Y, et al. Long-term outcomes of 95 children with moderate aplastic anemia treated with horse antithymocyte globulin and cyclosporine. Pediatr Blood Cancer. 2017; 64(5)doi: 10.1002/pbc.26305

60. [Internet] Cg. Efficacy and Safety of Eltrombopag + CSA in Patients With Moderate Aplastic Anemia (EMAA) (EMAA). 11 May 2016. Bethesda (MD): National Library of Medicine;

61. Maciejewski JP, Sloand EM, Nunez O, Boss C, Young NS. Recombinant humanized anti-IL-2 receptor antibody (daclizumab) produces responses in patients with moderate aplastic anemia. Blood. 2003; 102(10):3584-6. DOI: 10.1182/blood-2003-04-1032 [PubMed: 12881307]

62. Sloand EM, Olnes MJ, Weinstein B, Wu C, Maciejewski J, Scheinberg P, et al. Long-term followup of patients with moderate aplastic anemia and pure red cell aplasia treated with daclizumab. Haematologica. 2010; 95(3):382-7. DOI: 10.3324/haematol.2009.013557 [PubMed: 20207845]

63. Li X, Shao Y, Ge M, Shi J, Huang J, Huang Z, et al. A promising immunosuppressive strategy of cyclosporine alternately combined with levamisole is highly effective for moderate aplastic anemia. Ann Hematol. 2013; 92(9):1239-47. DOI: 10.1007/s00277-013-1764-7 [PubMed: 23620110]

64. Socie G, Rosenfeld S, Frickhofen N, Gluckman E, Tichelli A. Late clonal diseases of treated aplastic anemia. Semin Hematol. 2000; 37(1):91-101. [PubMed: 10676914]

65. de Planque MM, Bacigalupo A, Wursch A, Hows JM, Devergie A, Frickhofen N, et al. Long-term follow-up of severe aplastic anaemia patients treated with antithymocyte globulin. Severe Aplastic Anaemia Working Party of the European Cooperative Group for Bone Marrow Transplantation (EBMT). Br J Haematol. 1989; 73(1):121-6. [PubMed: 2803967]

••66. Yoshizato T, Dumitriu B, Hosokawa K, Makishima H, Yoshida K, Townsley D, et al. Somatic Mutations and Clonal Hematopoiesis in Aplastic Anemia. N Engl J Med. 2015; 373(1):35-47. doi:10.1056/NEJMoa1414799. A comprehensive analysis of clonal hematopoiesis in 439 patients with aplastic anemia using NGS showing clonal hematopoiesis in half of the patients, with a third of the patients carrying mutations in myeloid cancer candidate genes. Mutations in PIGA, BCOR and BCORL1 correlated with better outcomes, while a subgroup of mutations including ASXL1 were associated with worse outcomes. [PubMed: 26132940]

67. Babushok DV, Perdigones N, Perin JC, Olson TS, Ye W, Roth JJ, et al. Emergence of clonal hematopoiesis in the majority of patients with acquired aplastic anemia. Cancer Genet. 2015; 208(4):115-28. DOI: 10.1016/j.cancergen.2015.01.007 [PubMed: 25800665]

68. Marsh JC, Mufti GJ. Clinical significance of acquired somatic mutations in aplastic anaemia. Int J Hematol. 2016; 104(2):159-67. DOI: 10.1007/s12185-016-1972-8 [PubMed: 27084249]

69. Tichelli A, Gratwohl A, Wursch A, Nissen C, Speck B. Late haematological complications in severe aplastic anaemia. Br J Haematol. 1988; 69(3):413-8. [PubMed: 3044440]

70. Sugimori C, Chuhjo T, Feng X, Yamazaki H, Takami A, Teramura M, et al. Minor population of CD55-CD59- blood cells predicts response to immunosuppressive therapy and prognosis in patients with aplastic anemia. Blood. 2006; 107(4):1308-14. DOI: 10.1182/blood-2005-06-2485 [PubMed: 16179371] 
71. Katagiri T, Sato-Otsubo A, Kashiwase K, Morishima S, Sato Y, Mori Y, et al. Frequent loss of HLA alleles associated with copy number-neutral $6 \mathrm{pLOH}$ in acquired aplastic anemia. Blood. 2011; 118(25):6601-9. DOI: 10.1182/blood-2011-07-365189 [PubMed: 21963603]

72. Betensky M, Babushok D, Roth JJ, Mason PJ, Biegel JA, Busse TM, et al. Clonal evolution and clinical significance of copy number neutral loss of heterozygosity of chromosome arm $6 \mathrm{p}$ in acquired aplastic anemia. Cancer Genet. 2016; 209(1-2):1-10. DOI: 10.1016/j.cancergen. 2015.10.002 [PubMed: 26702937]

-73. Babushok DV, Duke JL, Xie HM, Stanley N, Atienza J, Perdigones N, et al. Somatic HLA Mutations Expose the Role of Class I-Mediated Autoimmunity in Aplastic Anemia and its Clonal Complications. Blood Adv. 2017 Oct 10; 1(22):1900-1910. Targeted NGS of HLA class I alleles and SNP-A analysis in 66 AA patients showed that $17 \%$ of patients have somatic HLA loss, with loss-of-function mutations targeting four specific HLA class I alleles. AA patients who carried these HLA alleles had a more severe disease course and more clonal evolution, suggesting that HLA class I-driven autoimmunity is a driving factor in AA pathogenesis, and likely a major force in clonal evolution in AA. [PubMed: 28971166]

-74. Zaimoku Y, Takamatsu H, Hosomichi K, Ozawa T, Nakagawa N, Imi T, et al. Identification of an HLA class I allele closely involved in the autoantigen presentation in acquired aplastic anemia. Blood. 2017; 129(21):2908-16. doi:10.1182/blood-2016-11-752378. A flow-cytometric screening of 28 AA patients with HLA-B*40:02 for leukocytes that lack the HLA-B*40:02 allele revealed a high frequency of somatic HLA-B*40:02 allele loss, through $6 \mathrm{p} \mathrm{LOH}$ and somatic mutations. The high prevalence of somatic loss of HLA-B*40:02 suggests that antigen presentation through this HLA-B allele plays a key role in AA pathogenesis. [PubMed: 28232583]

75. Narita A, Muramatsu H, Sekiya Y, Okuno Y, Sakaguchi H, Nishio N, et al. Paroxysmal nocturnal hemoglobinuria and telomere length predicts response to immunosuppressive therapy in pediatric aplastic anemia. Haematologica. 2015; 100(12):1546-52. DOI: 10.3324/haematol.2015.132530 [PubMed: 26315930]

76. Kulagin A, Lisukov I, Ivanova M, Golubovskaya I, Kruchkova I, Bondarenko S, et al. Prognostic value of paroxysmal nocturnal haemoglobinuria clone presence in aplastic anaemia patients treated with combined immunosuppression: results of two-centre prospective study. Br J Haematol. 2014; 164(4):546-54. DOI: 10.1111/bjh.12661 [PubMed: 24261566]

77. Zhao X, Zhang L, Jing L, Zhou K, Li Y, Peng G, et al. The role of paroxysmal nocturnal hemoglobinuria clones in response to immunosuppressive therapy of patients with severe aplastic anemia. Ann Hematol. 2015; 94(7):1105-10. DOI: 10.1007/s00277-015-2348-5 [PubMed: 25784221]

78. Tutelman PR, Aubert G, Milner RA, Dalal BI, Schultz KR, Deyell RJ. Paroxysmal nocturnal haemoglobinuria phenotype cells and leucocyte subset telomere length in childhood acquired aplastic anaemia. Br J Haematol. 2014; 164(5):717-21. DOI: 10.1111/bjh.12656 [PubMed: 24236830]

79. Maciejewski JP, Rivera C, Kook H, Dunn D, Young NS. Relationship between bone marrow failure syndromes and the presence of glycophosphatidyl inositol-anchored protein-deficient clones. Br J Haematol. 2001; 115(4):1015-22. [PubMed: 11843844]

80. Heuser M, Schlarmann C, Dobbernack V, Panagiota V, Wiehlmann L, Walter C, et al. Genetic characterization of acquired aplastic anemia by targeted sequencing. Haematologica. 2014; 99(9):e165-7. DOI: 10.3324/haematol.2013.101642 [PubMed: 24907358]

•81. Kulasekararaj AG, Jiang J, Smith AE, Mohamedali AM, Mian S, Gandhi S, et al. Somatic mutations identify a subgroup of aplastic anemia patients who progress to myelodysplastic syndrome. Blood. 2014; 124(17):2698-704. A targeted NGS analysis of 150 AA patients showing a that a fifth of AA patients carry somatic mutations in genes associated with myeloid malignancies. Most frequently, mutations involve $A S X L 1, D N M T 3 A$ and $B C O R$. Presence of somatic mutations was associated with $40 \%$ risk of transformation to MDS. DOI: $10.1182 /$ blood-2014-05-574889 [PubMed: 25139356]

82. Lane AA, Odejide O, Kopp N, Kim S, Yoda A, Erlich R, et al. Low frequency clonal mutations recoverable by deep sequencing in patients with aplastic anemia. Leukemia. 2013; 27(4):968-71. doi:leu201330 [pii] 10.1038/leu.2013.30. [PubMed: 23370706] 
83. Huang J, Ge M, Lu S, Shi J, Li X, Zhang J, et al. Mutations of ASXL1 and TET2 in aplastic anemia. Haematologica. 2015; 100(5):e172-5. DOI: 10.3324/haematol.2014.120931 [PubMed: 25596262]

84. Scheinberg P, Nunez O, Young NS. Retreatment with rabbit anti-thymocyte globulin and ciclosporin for patients with relapsed or refractory severe aplastic anaemia. Br J Haematol. 2006; 133(6):622-7. DOI: 10.1111/j.1365-2141.2006.06098.x [PubMed: 16704436]

85. Kamio T, Ito E, Ohara A, Kosaka Y, Tsuchida M, Yagasaki H, et al. Relapse of aplastic anemia in children after immunosuppressive therapy: a report from the Japan Childhood Aplastic Anemia Study Group. Haematologica. 2011; 96(6):814-9. DOI: 10.3324/haematol.2010.035600 [PubMed: 21422115]

86. Fuhrer M, Burdach S, Ebell W, Gadner H, Haas R, Harbott J, et al. Relapse and clonal disease in children with aplastic anemia (AA) after immunosuppressive therapy (IST): the SAA 94 experience. German/Austrian Pediatric Aplastic Anemia Working Group. Klin Padiatr. 1998; 210(4):173-9. DOI: 10.1055/s-2008-1043875 [PubMed: 9743949]

87. Scheinberg P, Nunez O, Weinstein B, Wu CO, Young NS. Activity of alemtuzumab monotherapy in treatment-naive, relapsed, and refractory severe acquired aplastic anemia. Blood. 2012; 119(2): 345-54. DOI: 10.1182/blood-2011-05-352328 [PubMed: 22067384]

88. Dufour C, Pillon M, Socie G, Rovo A, Carraro E, Bacigalupo A, et al. Outcome of aplastic anaemia in children. A study by the severe aplastic anaemia and paediatric disease working parties of the European group blood and bone marrow transplant. Br J Haematol. 2015; 169(4):565-73. DOI: 10.1111/bjh.13297 [PubMed: 25683884]

89. Kosaka Y, Yagasaki H, Sano K, Kobayashi R, Ayukawa H, Kaneko T, et al. Prospective multicenter trial comparing repeated immunosuppressive therapy with stem-cell transplantation from an alternative donor as second-line treatment for children with severe and very severe aplastic anemia. Blood. 2008; 111(3):1054-9. DOI: 10.1182/blood-2007-08-099168 [PubMed: 17989314]

90. Champlin RE, Ho WG, Feig SA, Winston DJ, Lenarsky C, Gale RP. Do androgens enhance the response to antithymocyte globulin in patients with aplastic anemia? A prospective randomized trial. Blood. 1985; 66(1):184-8. [PubMed: 4005428]

91. Doney K, Pepe M, Storb R, Bryant E, Anasetti C, Appelbaum FR, et al. Immunosuppressive therapy of aplastic anemia: results of a prospective, randomized trial of antithymocyte globulin (ATG), methylprednisolone, and oxymetholone to ATG, very high-dose methylprednisolone, and oxymetholone. Blood. 1992; 79(10):2566-71. [PubMed: 1586708]

92. Chuhjo T, Yamazaki H, Omine M, Nakao S. Danazol therapy for aplastic anemia refractory to immunosuppressive therapy. Am J Hematol. 2008; 83(5):387-9. DOI: 10.1002/ajh.21118 [PubMed: 18161784]

93. Tisdale JF, Dunn DE, Geller N, Plante M, Nunez O, Dunbar CE, et al. High-dose cyclophosphamide in severe aplastic anaemia: a randomised trial. Lancet. 2000; 356(9241):15549. DOI: 10.1016/S0140-6736(00)03126-3 [PubMed: 11075769]

94. Brodsky RA, Sensenbrenner LL, Jones RJ. Complete remission in severe aplastic anemia after high-dose cyclophosphamide without bone marrow transplantation. Blood. 1996; 87(2):491-4. [PubMed: 8555470]

95. Zhang F, Zhang L, Jing L, Zhou K, Wang H, Peng G, et al. High-dose cyclophosphamide compared with antithymocyte globulin for treatment of acquired severe aplastic anemia. Exp Hematol. 2013; 41(4):328-34. DOI: 10.1016/j.exphem.2013.01.001 [PubMed: 23313080]

96. Brodsky RA, Chen AR, Dorr D, Fuchs EJ, Huff CA, Luznik L, et al. High-dose cyclophosphamide for severe aplastic anemia: long-term follow-up. Blood. 2010; 115(11):2136-41. DOI: 10.1182/ blood-2009-06-225375 [PubMed: 20018919]

97. Scheinberg P, Townsley D, Dumitriu B, Scheinberg P, Weinstein B, Daphtary M, et al. Moderatedose cyclophosphamide for severe aplastic anemia has significant toxicity and does not prevent relapse and clonal evolution. Blood. 2014; 124(18):2820-3. DOI: 10.1182/blood-2014-05-573642 [PubMed: 25185712]

98. [Internet] Cg. Eltrombopag Combined With Cyclosporine as First Line Therapy in Patients With Severe Acquired Aplastic Anemia (SOAR). 10 May 2017. Bethesda (MD): National Library of Medicine; 
99. [Internet] Cg. hATG+CsA vs hATG+CsA+Eltrombopag for SAA (RACE). 10 October 2016. Bethesda (MD): National Library of Medicine; 


\section{Diagnosis}

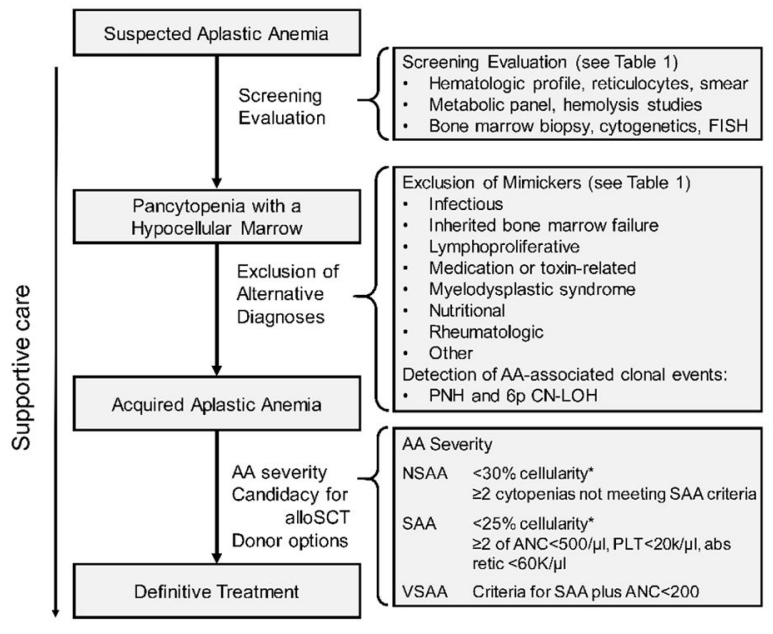

\section{Treatment}

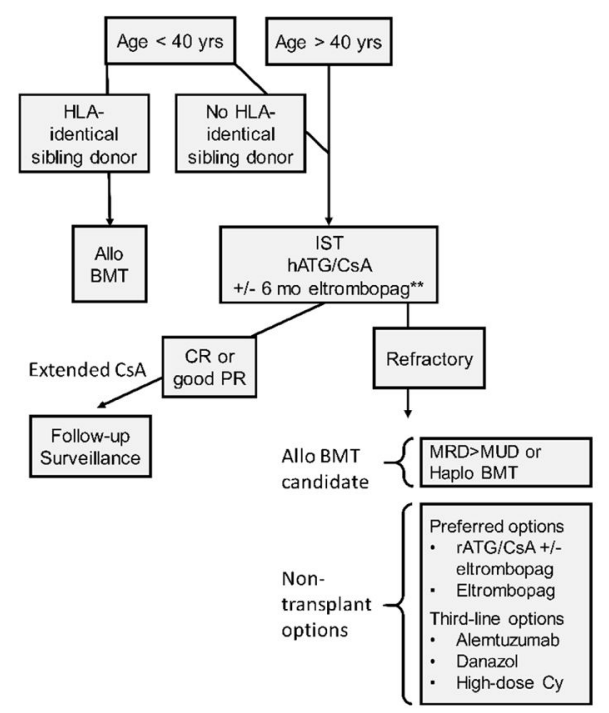

Figure 1. Approach to diagnosis and treatment of acquired aplastic anemia Initial screening evaluation of a patient with aplastic anemia is required to document pancytopenia with a hypocellular marrow, followed by testing to exclude alternative diagnoses. Aplastic anemia severity and outcomes of a transplant evaluation factor into determining an optimal treatment strategy. Patients with Severe or Very Severe Aplastic Anemia (SAA/VSAA) 40 years of age or younger with an HLA-matched sibling donor should undergo an evaluation for an allogeneic bone marrow transplant; older patients or patients without an HLA-identical sibling donor should be evaluated for frontline immunosuppressive therapy (IST) with horse ATG and CsA. **Based on recent data showing superior hematologic outcomes with the addition of eltrombopag [4], addition of 6 months of eltrombopag to standard IST in patients without pre-existing cytogenetic abnormalities can be considered. Cyclosporine A should be continued for $\sim 12$ months of therapy, followed by a slow taper to reduce relapse rates. Salvage therapies include alternative transplant modalities and a variety of nontransplant options. $A A$, aplastic anemia; 
$P N H$, paroxysmal nocturnal hemoglobinuria; $6 \mathrm{p} C N-\mathrm{LOH}$, copy number-neutral loss of heterozygosity of chromosome arm 6p; alloSCT, allogeneic stem cell transplant; NSAA, nonsevere aplastic anemia; $S A A$, severe aplastic anemia; $V S A A$, very severe aplastic anemia. *Cellularity criteria are determined on adequate bone marrow biopsy, and hypoplastic marrow can either be diagnosed on total cellularity or on bone marrow biopsy with $<50$ percent normal cellularity in which $<30$ percent of the cells are hematopoietic. $H L A$, human leukocyte antigen; alloBMT, allogeneic bone marrow transplant; IST, immunosuppressive therapy; $h A T G$, horse antithymocyte globulin; CsA, cyclosporine A; $C R$, complete response; $P R$, partial response; $C y$, cyclophosphamide; $M R D$, matched related donor; $M U D$, matched unrelated donor; haplo BMT, haploidentical bone marrow transplant. 


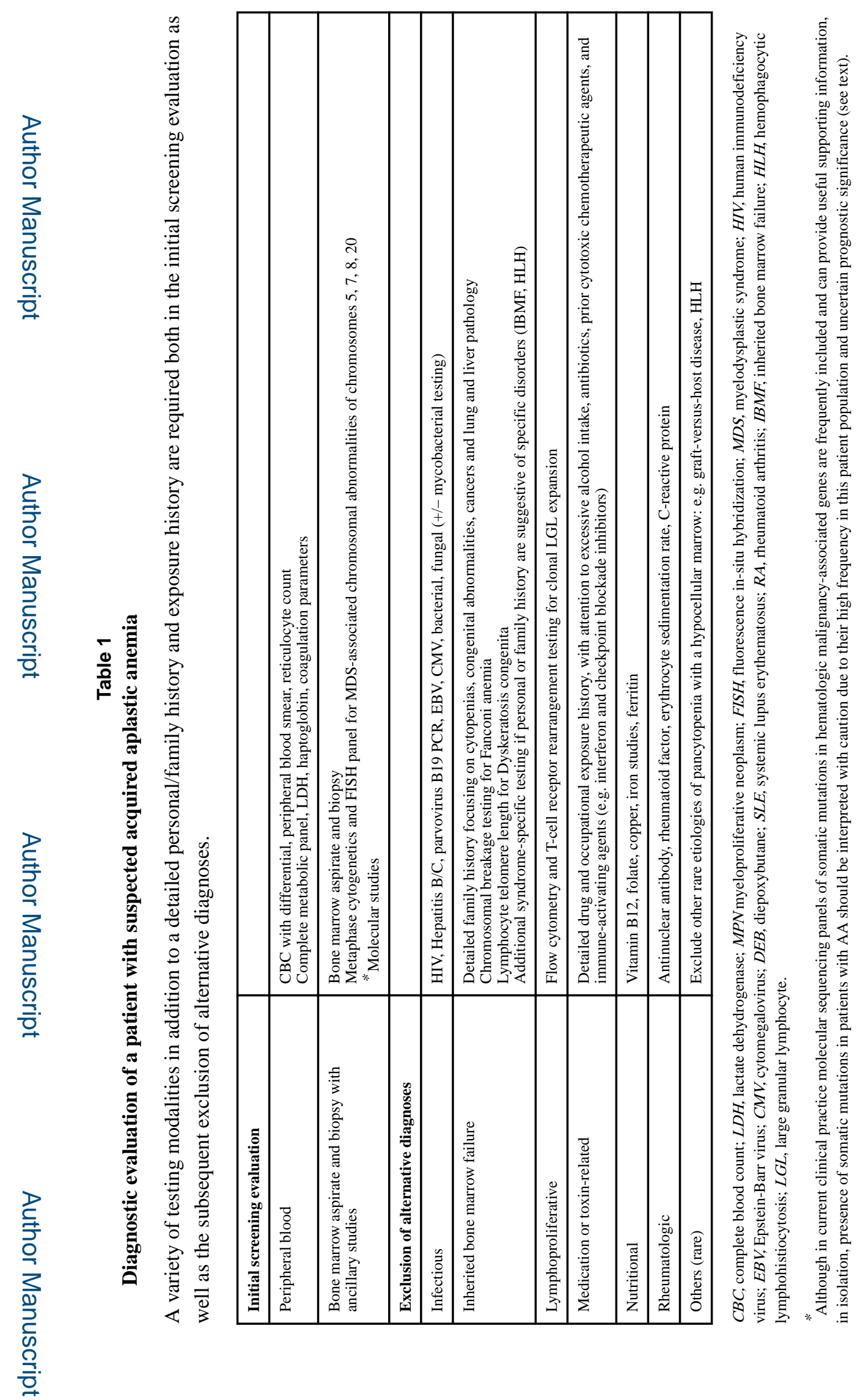

Curr Treat Options Oncol. Author manuscript; available in PMC 2018 November 16. 


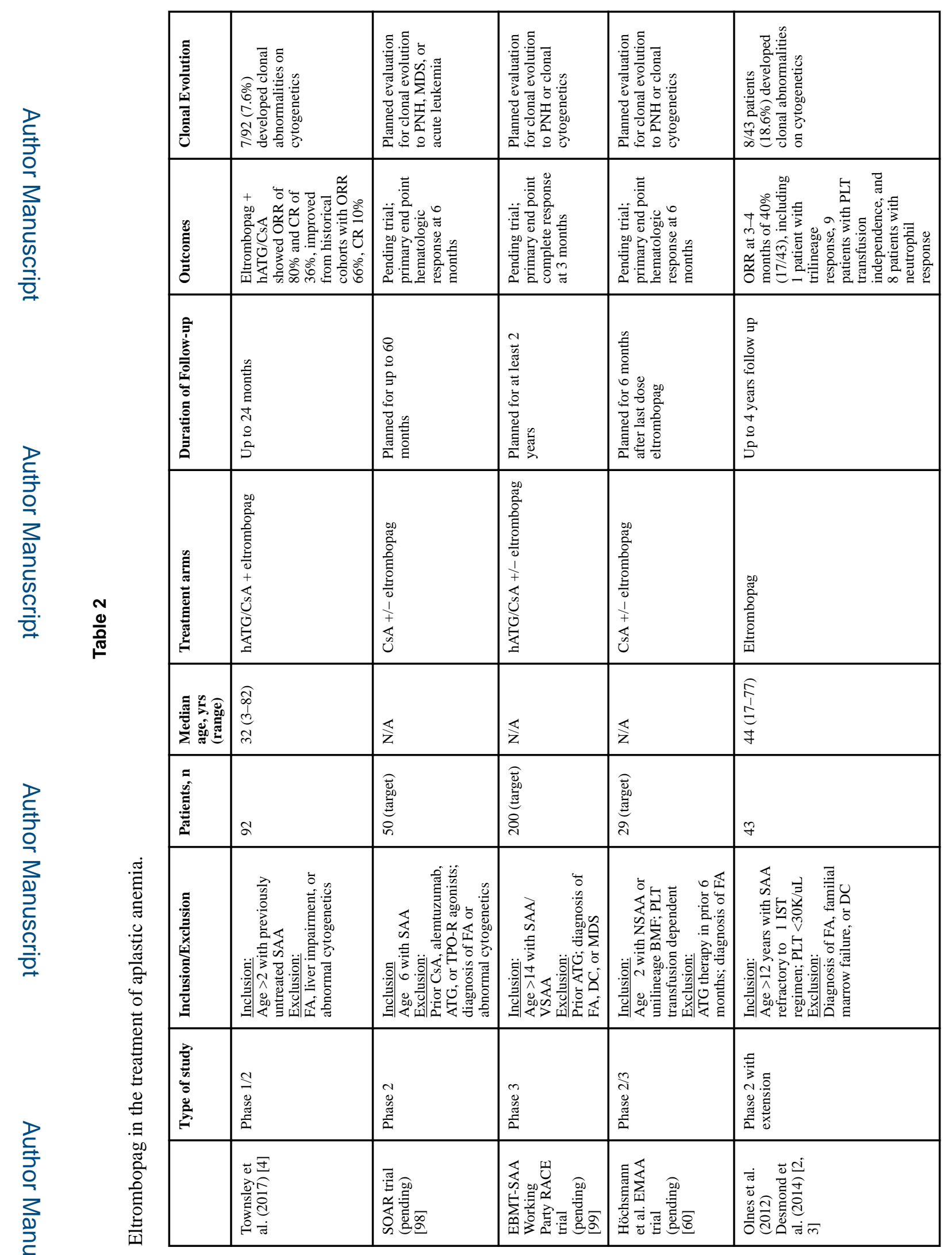

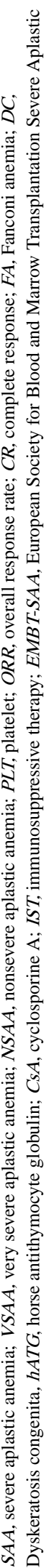

Curr Treat Options Oncol. Author manuscript; available in PMC 2018 November 16. 


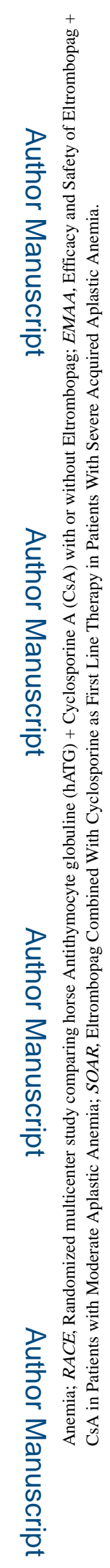

